\title{
Silencing of Foxp3 delays the growth of murine melanomas and modifies the tumor immunosuppressive environment
}

This article was published in the following Dove Press journal:

OncoTargets and Therapy

12 January 2016

Number of times this article has been viewed

\author{
Moisés A Franco-Molina* \\ Diana F Miranda- \\ Hernández* \\ Edgar Mendoza-Gamboa \\ Pablo Zapata-Benavides \\ Erika E Coronado-Cerda \\ Crystel A Sierra-Rivera \\ Santiago Saavedra-Alonso \\ Reyes S Taméz-Guerra \\ Cristina Rodríguez-Padilla
}

Immunology and Virology Department, Biological Sciences Faculty, University Autonoma of Nuevo León (UANL), San Nicolás de los Garza, Nuevo León, Mexico

*These authors contributed equally to this work
Correspondence: Moisés A Franco-

Molina

Immunology and Virology Department,

Biological Sciences Faculty, University

Autonoma of Nuevo León (UANL), PO

Box 46 "F", San Nicolás de los Garza

66450, Nuevo León, Mexico

Tel +528183294115

$\mathrm{Fax}+528183524212$

Email moyfranco@gmail.com
Abstract: Forkhead box p3 (Foxp3) expression was believed to be specific for T-regulatory cells but has recently been described in non-hematopoietic cells from different tissue origins and in tumor cells from both epithelial and non-epithelial tissues. The aim of this study was to elucidate the role of Foxp3 in murine melanoma. The B16F10 cell line Foxp3 silenced with small interference Foxp3 plasmid transfection was established and named B16F10.1. These cells had lower levels of Foxp3 mRNA (quantitative real-time reverse transcription-polymerase chain reaction [0.235-fold]), protein (flow cytometry [0.02\%]), CD25+ expression $(0.06 \%)$, cellular proliferation (trypan blue staining), and interleukin (IL)-2 production (enzyme-linked immunosorbent assay [72.35 pg/mL]) than those in B16F10 wild-type (WT) cells $(P<0.05)$. Subcutaneous inoculation of the B16F10.1 cell line into C57BL/6 mice delayed the time of visible tumor appearance, increased the time of survival, and affected the weight of tumors, and also decreased the production of IL-10, IL-2, and transforming growth factor beta compared with mice inoculated with the B16F10 WT cell line. The B16F10.1 cells derived from tumors and free of T-cells (isolated by Dynabeads and plastic attachment) expressed relatively lower levels of Foxp3 and $\mathrm{CD} 25^{+}$than B16F10 WT cells $(P<0.05)$ in a time-dependent manner. The population of tumor-infiltrating lymphocytes of $\mathrm{T} \mathrm{CD} 4^{+}$cells $\left(\mathrm{CD} 4^{+}, \mathrm{CD} 4^{+} \mathrm{CD} 25^{+}\right.$, and $\left.\mathrm{CD} 4^{+} \mathrm{CD} 25^{+} \mathrm{Foxp}^{+}\right)$increased in a time-dependent manner $(P<0.05)$ in tumors derived from B16F10 WT cells and decreased in tumors derived from B16F10.1 cells. Similar data were obtained from spleen cells. These results suggest that, in melanomas, Foxp3 partly induces tumor growth by modifying the immune system at the local and peripheral level, shifting the environment toward an immunosuppressive profile. Therapies incorporating this transcription factor could be strategies for cancer treatment.

Keywords: melanoma, Foxp3, cancer, T-regulatory cells

\section{Introduction}

Forkhead box p3 (Foxp3) has been reported in several tumor cell lines and tumors of patients. ${ }^{1,2}$ Foxp3 expression in cancer cells induced immune evasion and reduced the growth of $\mathrm{CD}^{+} \mathrm{CD} 25^{+} \mathrm{T}$-cells. ${ }^{3}$ Foxp3 is expressed in T-regulatory cells (Tregs), metastatic melanoma tissue, and tumor cell lines from melanomas. ${ }^{4}$ Furthermore, at a clinical level, Foxp3 expression in tumors is associated with worse overall survival. T-cell function may be addressed by Foxp3 and tumor-associated Foxp3, but it is not known if intratumoral Foxp3 expression affects the immune system at the level of the tumor microenvironment. ${ }^{4}$ In some studies, Foxp3 expression induced a suppressive phenotype in human T-cells, but there are some populations of T-cells that, despite Foxp3 expression, are not considered as Tregs. ${ }^{5,6}$ Patients with metastatic melanoma have increased migration and/or proliferation of CD4 ${ }^{+}$Tregs in intratumoral regions compared to peritumoral 
regions, and these values are higher in peripheral blood of cancer patients compared with healthy donors. ${ }^{7}$ The presence of tumor-infiltrating lymphocytes (TIL), including the Treg phenotype, and the induction of a immunosuppressive tumor microenvironment are not clear, but it has been suggested that an increase in the conversion of Foxp3- T-cells into Foxp3 $3^{+}$ $\mathrm{T}$-cells may occur in the presence of transforming growth factor beta-1 (TGF- $\beta 1)$ and retinoic acid. ${ }^{8}$

This study analyzed the effect of silencing Foxp3 expression on tumorigenicity and the tumor microenvironment in murine melanomas in vitro and in vivo. Our results demonstrated that silencing Foxp3 in B16F10 melanoma cells in vitro decreased cell viability and the expression of Foxp3 mRNA, CD25+, and interleukin (IL)-2. Silencing in vivo delayed the time of visible tumor appearance, increased the time of survival, affected the weight of tumors, and partly avoided the immunosuppressive cellular phenotype within the tumor. These results suggest Foxp3 could serve as a target therapeutic in melanoma treatment.

\section{Materials and methods}

\section{BI6FIO murine melanoma cell line}

The murine B16F10 melanoma cell line was obtained from the American Type Culture Collection (ATCC), Manassas, VA, USA, and cultivated in Dulbecco's Modified Eagle Medium (DMEM/F12; Thermo Fisher Scientific, St Louis, MO, USA) supplemented with $10 \%$ fetal bovine serum (FBS; Thermo Fisher Scientific, Waltham, MA, USA), 100 U/mL penicillin, and $100 \mu \mathrm{g} / \mathrm{mL}$ streptomycin. The cells were maintained in culture flasks at $37^{\circ} \mathrm{C}$ in a humidified atmosphere with $5 \% \mathrm{CO}_{2}$. The protocol for the animal study was approved by the Animal Committee of the Faculty of Biological Science of University Autonomous of Nuevo Leon.

\section{Animals}

C57BL/6 mice (6 weeks old) were acquired from Harlan México, SA de CV. The mice were housed according to experimental protocols that were approved by the Ethics Review Committee for Animal Experimentation of the Faculty of Biological Sciences of the University Autonomous of Nuevo León.

\section{Preparation of polyethylenimine-DNA complexes}

Polyethylenimine (PEI, 25 kDa branched form; SigmaAldrich Co., St Louis, MO, USA) stock solution was prepared at a concentration of $4.3 \mathrm{mg} / \mathrm{mL}(0.1 \mathrm{M}$ in nitrogen $)$ in water. The DNA was at $3 \mathrm{nmol}$ of phosphate per microgram, and
$1 \mu \mathrm{L}$ of the $0.1 \mathrm{M}$ PEI solution contained $100 \mathrm{nmol}$ of amine nitrogen. The resulting charge ratio was expressed as the ratio of PEI nitrogen to DNA phosphorus (N:P). A 10:1 N:P was used for the experiments, which corresponds to a 1.29:1 PEI:DNA weight ratio.

\section{Foxp3 small interference RNA expression constructs}

Three oligo pairs (sense and antisense) for Foxp3-small interference RNA (siRNA) were designed using siRNA design guidelines online software (Ambion, Austin, TX, USA), synthesized at a concentration of $0.05 \mu \mathrm{g}$ (Ambion), and used to create three recombinant plasmids (termed Foxp3-siRNA1, Foxp3-siRNA2, and Foxp3-siRNA3). For plasmid Foxp3-1, the oligos were 5'-CAUGGACUACUUCAAGUACtt-3' and $3^{\prime}$-GUACUUGAAGUAGUCCAUGtt-5' ; for plasmid Foxp3-2, 5'-AUCUACCAUUGGUUUACUCtt-3' and $3^{\prime}$-GAGUAAACCAAUGGUAGAUtt-5'; and for plasmid Foxp3-3, 5'-UUUGAGUUUCGCAAGAAGAtt-3' and 3'-UCUUCUUGCGAAACUCAAAtt-5'. The oligos were resuspended to a final concentration of $1 \mu \mathrm{g} / \mu \mathrm{L}^{-1}$, annealed, and ligated into plasmid of expression green fluorescence protein-N2 (pEGFP-N2; Clontech, Palo Alto, CA, USA). The constructs were tested by enzymatic digestion with HindIII and were produced on a large scale and purified with the EndoFree Plasmid Giga Kit (Qiagen NV, Venlo, the Netherlands), according to the manufacturer's instructions.

\section{Effect of small interference Foxp3 on BI6FI0-transfected melanoma cells}

Briefly, 24 hours before transfection, $5 \times 10^{5}$ B16F10 wildtype (WT) cells were seeded in 96-well culture plates. Thereafter, B16F10 WT cells were transfected with small interference Foxp3 (siFoxp3) plasmids (siFoxp3-1, siFoxp3-2, and siFoxp3-3) and pEGFP-N2 (as a negative control). The complex PEI:DNA was performed as described previously. At 72 hours, 3-(4,5-dimethylthiazolyl-2)-2, 5-diphenyltetrazolium bromide (MTT) assay was performed for cell viability analysis. The MTT solution was prepared by mixing $0.025 \mathrm{~g}$ of MTT (Sigma-Aldrich Co.) with $5 \mathrm{~mL}$ of phosphate-buffered saline (PBS) for a final MTT concentration of $5 \mathrm{mg} / \mathrm{mL}$. Then, $20 \mu \mathrm{L}$ of this solution was added to each well. The cells were incubated with the MTT solution at $37^{\circ} \mathrm{C}$ for $2-4$ hours until a purple precipitate was visible, followed by removal of the medium and addition of $80 \mu \mathrm{L}$ dimethylsulfoxide to each well. The samples were rocked for 10 minutes. The optical density was determined at $570 \mathrm{~nm}$ using a microplate autoreader (Microplate Autoreader 
EL311; BioTek Instruments Inc., Winooski, VA, USA). Data are presented as the percentage of relative cell viability \pm standard error.

\section{Generation of silenced Foxp3 BI6FIO clones}

siFoxp3-1 plasmids were selected for pre-transfection of the B16F10 WT cells. The B16F10 WT cells were adjusted to $5 \times 10^{5}$ cells/well in six-well plates and transfected as previously described. At 48 hours, the cells were visualized in confocal microscopy to corroborate the presence of green fluorescent protein in positive B16F10-transfected cells. Then, $1 \mathrm{mg} / \mathrm{mL}$ G418 (Geneticin; Thermo Fisher Scientific), a neomycin analog, was added and was gradually decreased as follows: $1 \mathrm{mg} / \mathrm{mL}$ for 4 days; $750 \mu \mathrm{g} / \mathrm{mL}$ for 4 days; $500 \mu \mathrm{g} / \mathrm{mL}$ for 4 days; and $250 \mu \mathrm{g} / \mathrm{mL}$ as a sustaining dose. At day 20 after transfection, G418-resistant clones were isolated. The selected cell colonies were transferred from $10 \mathrm{~mm}$ dishes to 96 -well plates and then to 24 -well plates. The selection was continued by replacing the media with G418 every 3 days. The G418-resistant clones were isolated once they were selected. Foxp3 mRNA and protein expression were analyzed. The selected clone was widely reproduced for further use (named B16F10.1). The B16F10 WT cells were cultured under identical conditions.

\section{Foxp3 mRNA expression}

Foxp3 mRNA expression in B16F10 WT and B16F10.1 cells (selected clones) was evaluated by quantitative real-time reverse transcription-polymerase chain reaction (qRT-PCR). After total RNA isolation and reverse transcription into cDNA, qRT-PCR was performed using the automated thermocycler PTC-200 (MJ Research, Watertown, MA, USA), the SYBR Supermix kit (Thermo Fisher Scientific), the RT ${ }^{2}$ PCR Primer Set for Foxp3 (SuperArray Biosciences, Bethesda, MD, USA), and $\beta$-actin as a reference gene ( $\mathrm{RT}^{2}$ PCR Primer Set; SuperArray Biosciences). The qRT-PCR thermocycling conditions for Foxp 3 were 10 minutes at $95^{\circ} \mathrm{C}$ for an initial hold, followed by 40 cycles of denaturation at $95^{\circ} \mathrm{C}$, annealing at $60^{\circ} \mathrm{C}$, and extension at $72^{\circ} \mathrm{C}$, all for 15 seconds. The qRTPCR thermocycling conditions for $\beta$-actin were 10 minutes at $95^{\circ} \mathrm{C}$ for an initial hold, followed by 40 cycles of denaturation at $95^{\circ} \mathrm{C}$ for 15 seconds and annealing/extension at $60^{\circ} \mathrm{C}$ for 60 seconds. Relative expression was analyzed using Rotor Gene software. For RT-PCR amplification, $20 \mu \mathrm{M}$ of forward 5'-GGCATCGTGATGGACTCCG-3' and reverse 3'-GCTGGAAGGTGGACAGCGA-5' primers was used for $\beta$-actin. The RT ${ }^{2}$ PCR Primer Set was used for
Foxp3 (SuperArray Biosciences) in a total reaction volume of $25 \mu \mathrm{L}$.

\section{Flow cytometry analysis}

To analyze the cellular expression levels of CD25+ and Foxp3, $1 \times 10^{6}$ B16F10 WT and B16F10.1 cells were stained using an anti-mouse CD25 antibody (eBioscience, San Diego, CA, USA) in a final volume of $100 \mu \mathrm{L}$ of flow cytometry staining buffer and incubated at $4^{\circ} \mathrm{C}$ for 30 minutes. An Fc block was added to the incubation buffer with anti-mouse CD25, and then the cells were washed in cold flow cytometry staining buffer. The cells were pelleted by centrifugation, the supernatant was discarded, and the cells were resuspended with a vortex pulse. Freshly prepared fixation/permeabilization working solution $(1 \mathrm{~mL})$ was added to the cells which were then incubated at $4^{\circ} \mathrm{C}$ for 30 minutes, washed twice with $2 \mathrm{~mL} 1 \times$ permeabilization buffer, and centrifuged to collect the cells. The supernatant was discarded, and an Fc block in $1 \times$ permeabilization buffer was added to the cells in a final volume of $100 \mu \mathrm{L}$ before incubation at $4^{\circ} \mathrm{C}$ for 15 minutes. An anti-mouse/rat Foxp3 (clone FJK-16s) antibody (eBioscience) in $1 \times$ permeabilization buffer was added without washing after the blocking step and incubated at $4{ }^{\circ} \mathrm{C}$ for 30 minutes in the dark. Subsequently, the cells were washed once with $2 \mathrm{~mL} 1 \times$ permeabilization buffer. The stained cells were collected by centrifugation after discarding the supernatant and resuspended in 1\% paraformaldehyde. The data were analyzed using a flow cytometer (EPICS ALTRA; Beckman Coulter, Fullerton, CA, USA).

\section{Proliferative response of BI6FIOWT and BI6FI0.I cells}

For analysis of cellular proliferation, the B16F10 WT and B16F10.1 melanoma cells $\left(2.5 \times 10^{5}\right.$ cells $)$ were plated in sixwell plates at $37^{\circ} \mathrm{C}$ in a $5 \% \mathrm{CO}_{2}$ atmosphere. The proliferation index was determined by a trypan blue exclusion assay at 24 hours, 48 hours, and 72 hours.

\section{Animal study}

Groups of 6-week-old C57BL/6 mice (ten mice per group) were subcutaneously inoculated in the right flank with B16F10 WT or B16F10.1 cells $\left(5 \times 10^{5}\right.$ cells/200 $\mu \mathrm{L}$ PBS $)$ and were monitored until tumor appearance was visible. Mouse survival was then determined. In a parallel study, mice inoculated with B16F10 WT or B16F10.1 cells were established. At euthanasia, the tumors and spleen were aseptically removed, and the weight and Foxp3 expression (qRT-PCR) were analyzed. Cytokine production (IL-2, 
interferon gamma [INF- $\gamma$ ], TGF- $\beta$, and IL-10) was assessed by enzyme-linked immunosorbent assay (ELISA) and flow cytometry (T-cells CD $4^{+}, \mathrm{CD} 4{ }^{+} \mathrm{CD} 25^{+}, \mathrm{CD} 4^{+} \mathrm{CD} 25^{+} \mathrm{FOXP} 3^{+}$ Tregs, and $\mathrm{CD}_{2} 5^{+}$expression). The procedures for each experiment are described in the following sections.

\section{TILs and BI6FIOWT or BI6FI0.I cell isolation from tumors}

The melanoma cells were removed from the tumors of mice inoculated with B16F10 WT (7 days, 14 days, and 21 days post tumor appearance) or B16F10.1 cells ( 7 days, 14 days, 21 days, and 28 days post tumor appearance). B16F10 WT and B16F10.1 cells were obtained from the tumor by washing the tumor tissues with DMEM/F12 using a sterile syringe. After washing several times, $15 \mathrm{~mL}$ of ammoniachloride-potassium (ammonia-chloride-potassium lysis buffer: $0.15 \mathrm{M} \mathrm{NH}_{4} \mathrm{Cl} ; 0.1 \mathrm{mM} \mathrm{KHCO}_{3} ; 0.1 \mathrm{mM}$ disodium ethylenediaminetetraacetic acid, $\mathrm{pH}$ 7.2) was added to the collected cells to remove red blood cells, and the cells were centrifuged at 1,600 rpm/10 minutes. To isolate the T-cells and the B16F10 WT or B16F10.1 cells from the tumor, the cells were resuspended in isolation buffer from the Dynabeads FlowComp Mouse Pan T (CD90.2) kit (Thermo Fisher Scientific) at a concentration of $1 \times 10^{8}$ cells $/ \mathrm{mL}$. The FlowComp TM mouse CD90.2 antibody from the kit was added to the cell suspension at a ratio of $25 \mu \mathrm{L}$ antibodies per $500 \mu \mathrm{L}$ cell suspension $\left(5 \times 10^{7}\right.$ cells), mixed, and incubated for 10 minutes at $2^{\circ} \mathrm{C}-8^{\circ} \mathrm{C}$. After incubation, the cells were washed by adding $2 \mathrm{~mL}$ of isolation buffer, centrifuged at 1,600 rpm for 8 minutes, and resuspended in $1 \mathrm{~mL}$ of isolation buffer. Resuspended FlowComp TM Dynabeads $(75 \mu \mathrm{L})$ were added to the tube, mixed, and incubated for 15 minutes at room temperature with rolling and tilting. The tubes were then placed on a magnet for a minimum of $1 \mathrm{~min}$ ute. The supernatants containing the melanoma cells were carefully collected while the tube was still on the magnet. The washing step was repeated once, and the supernatants were collected. Finally, the supernatants were cultured in a $25 \mathrm{~cm}^{2}$ cell culture flask and incubated at $37^{\circ} \mathrm{C}$ in a $5 \% \mathrm{CO}_{2}$ atmosphere for 3 hours. After adherence of the intratumoral B16F10 WT and B16F10.1 cells to the flask, they were washed with PBS to remove cell debris and other cell types. The concentration of intratumoral B16F10 WT and B16F10.1 melanoma cells was adjusted to $1 \times 10^{6}$ cells in a final volume of $100 \mu \mathrm{L}$ of flow cytometry staining buffer (eBioscience). These cells were analyzed for Foxp $3^{+}$and $\mathrm{CD} 25^{+}$expression as described earlier. The TIL cells remained on the magnet and were collected after the tube was removed and analyzed by flow cytometry.

\section{Measurement of cytokine production}

B16F10 WT or B16F10.1 melanoma cells $\left(5 \times 10^{5}\right.$ cells $/ \mathrm{mL}$ $\mathrm{DMEM} / \mathrm{F} 12$ supplemented with $10 \% \mathrm{FBS}$ ) were cultured for 48 hours at $37^{\circ} \mathrm{C}$ in a $5 \% \mathrm{CO}_{2}$ atmosphere. The supernatants were collected and stored at $-20^{\circ} \mathrm{C}$ for subsequent analysis of cytokine production (IFN- $\gamma$, IL-2, TGF- $\beta$, and IL-10; Thermo Fisher Scientific) by ELISA. The tumors were aseptically collected and macerated by adding $1 \times$ PBS at a proportion of $400 \mathrm{~g}$ of tumor: $1 \mathrm{~mL}$ of PBS. The supernatants were collected and stored at $-20^{\circ} \mathrm{C}$ until use. Protein quantification was analyzed using the Lowry assay and adjusted to $1 \mathrm{mg}$ protein concentration. Then, ELISA experiments were performed for cytokine production (IFN- $\gamma$, IL-2, TGF- $\beta$, and IL-10; Thermo Fisher Scientific), according to the manufacturer's specifications. The absorbance was determined at $450 \mathrm{~nm}$ using a microplate autoreader (EL311; Bio-Tek Instruments).

\section{Regulatory T-cells in TIL and spleen cells in murine melanomas}

TIL and spleen cells were obtained during murine melanoma growth. For analysis of Tregs, a Human Regulatory T Cell Staining Kit (eBioscience), including fluorescein isothiocyanate $\mathrm{CD} 4$, phycoerythrin (PE) CD25, and PEcyanin 5 Foxp3, was used. Tregs were analyzed according to the manufacturer's instructions. Isotype-negative controls included a mouse isotype matched to a nonrelevant immunoglobulin to define the positive population. After gating the TIL population and spleen T-cells, the $\mathrm{CD} 4{ }^{+} \mathrm{CD} 25^{+}$and $\mathrm{CD} 4^{+} \mathrm{CD} 25^{+} \mathrm{Foxp} 3^{+}$populations were sequentially gated and analyzed. The percentage of Foxp $3^{+}$cells $\left(\mathrm{CD} 4^{+} \mathrm{CD} 25^{+} \mathrm{Foxp}^{+}\right)$ was evaluated in the $\mathrm{CD} 4^{+} \mathrm{CD} 25^{+}$population. The data were analyzed using a flow cytometer.

\section{Analysis of $\mathrm{CD}_{25} 5^{+}$expression in TIL and spleen cells in murine melanoma}

To analyze the cellular expression levels of $\mathrm{CD} 25^{+}$during murine melanoma growth, $1 \times 10^{6} \mathrm{TIL}$ and spleen T-cells were stained using an anti-mouse $\mathrm{CD} 25^{+}$antibody (PE; eBioscience) in a final volume of $100 \mu \mathrm{L}$ of flow cytometry staining buffer and were incubated at $4^{\circ} \mathrm{C}$ for 30 minutes. The stained cells were collected by centrifugation after discarding the supernatant and were resuspended in 1\% paraformaldehyde. The data were analyzed using a flow cytometer.

\section{Statistical analysis}

The results of the cytokine ELISA were analyzed using Student's $t$-test. Differences between the cells were analyzed by the Dunnett's test. All differences reported in the results 
were significant $(P<0.05)$. Each analysis was repeated in triplicate.

\section{Results \\ Characterization of plasmids}

The siRNA Foxp3-specific constructions (siFoxp3-1, siFoxp3-2, and siFoxp3-3) were elaborated. To confirm the correct ligation, the plasmids were treated with HindIII that resulted in a fragment size consistent with the size of the plasmid (the control vector pEGFP-N2 was $4.7 \mathrm{kbp}$ ). The siRNA sequences corresponding to each plasmid of 5,381 bp (siFoxp3-1, siFoxp3-2, and siFoxp3-3) were determined by $1 \%$ agarose gel electrophoresis analysis (Figure 1 ).

\section{Effect of siRNA Foxp3 on cell viability of BI6FIOWT}

To test whether Foxp3 is required for B16F10 WT cell proliferation or survival, we silenced Foxp3 expression in the murine melanoma cell line using the siRNA against Foxp3 (siFoxp3-1, siFoxp3-2, and siFoxp3-3). The plasmid transfections with siFoxp3-3 (94.99\%) significantly decreased the relative cell viability compared with siFoxp3-1 (21.32\%) and siFoxp3-2 (9.84\%) in the B16F10 WT cell line. The untransfected B16F10 WT cell line and the pEGFP-N2 plasmid were used as controls (Figure 2). Foxp3 expression was determined by qRT-PCR in each B16F10 WT group treated with or without siFoxp3-1, siFoxp3-2, and siFoxp3-3. All siFoxp3 plasmid transfections significantly $(P<0.005)$ decreased Foxp3 (siFoxp3-1 [0.236-fold], siFoxp3-2 [0.546-fold], and siFoxp3-3 [0.065-fold]) expression compared with B16F10

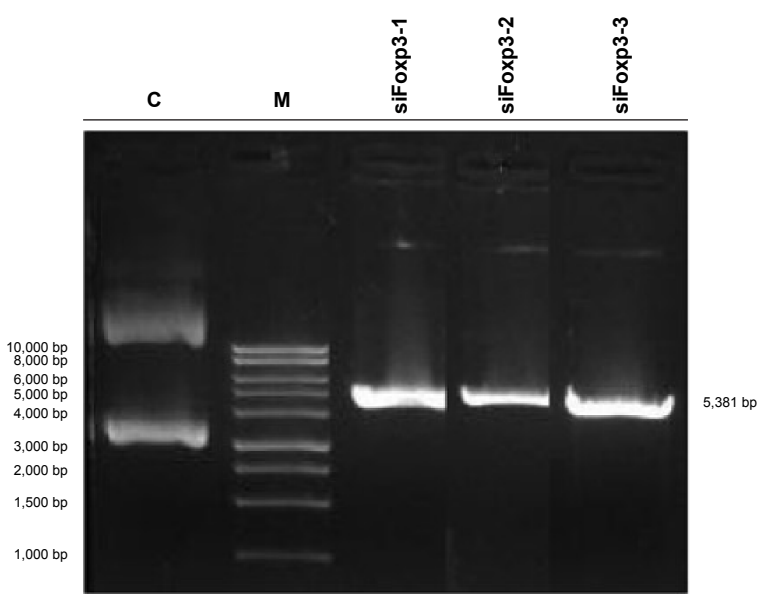

Figure I Characterization of the Foxp3 recombinant plasmids.

Notes: Lane C, plasmid pEGFP-N2, used as transfection control; the recombinant plasmids siFoxp3-I, siFoxp3-2, and siFoxp3-3 were digested with the enzyme HindllI. Lane $M$ shows the molecular weight marker DL 10000 DNA ladder.

Abbreviations: Lane C, plasmid pEGFP-N2 used as transfection control; Lane M, molecular weight marker; siFoxp3, the recombinant plasmids I-3; pEGFP-N2, plasmid of expression green fluorescence protein-N2.

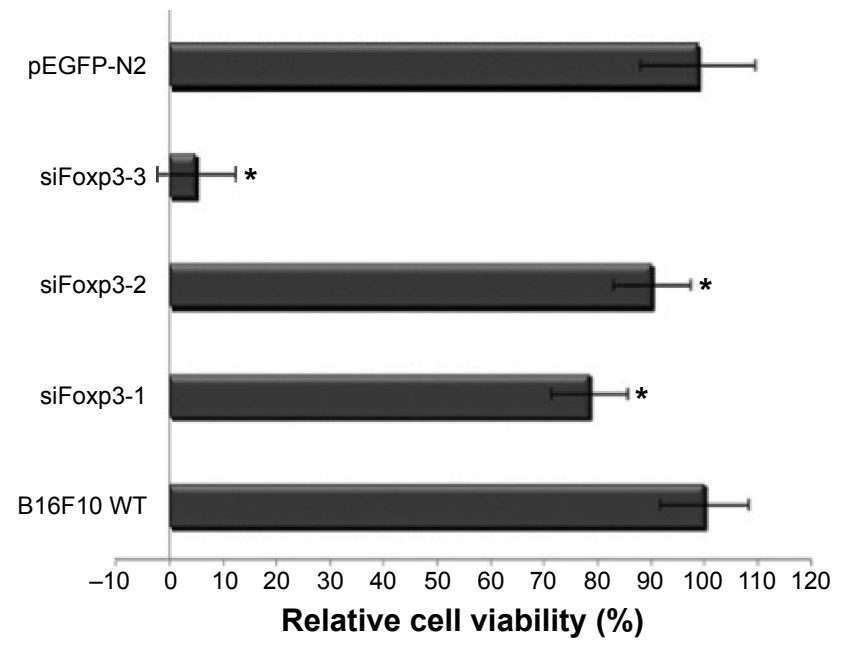

Figure 2 Foxp3 siRNA inhibits BI6FI0 WT murine melanoma cell proliferation. Notes: BI6FIO WT cells $\left(5 \times 10^{3}\right.$ cells) were harvested and incubated at $37^{\circ} \mathrm{C}$ in a $5 \%$ $\mathrm{CO}_{2}$ atmosphere for 24 hours. Thereafter, the cells were transfected with the siRNA (siFoxp3-I, siFoxp3-2, and siFoxp3-3) for 48 hours. Analysis of cell proliferation by MTT assay was performed. The values of relative cell viability (\%) using the siRNA's were compared with the values of relative cell viability of the BI6FIO WT cells without transfection. The pEGFP-N2 plasmid was used as control. Values are the means of the average cell viability for three independent experiments \pm standard deviation. $* P<0.05$.

Abbreviations: WT, wild type; siRNA, small interference RNA; siFoxp3, the recombinant plasmids I -3; pEGFP-N2, plasmid of expression green fluorescence protein-N2; MTT, 3-(4,5-dimethylthiazolyl-2)-2, 5-diphenyltetrazolium bromide.

WT cells (onefold; Figure 3). We chose the siFoxp3-1 plasmid for establishing a stable transfection in the B16F10 cells, because the effect on cell growth allowed the establishment of a cell line with lower Foxp3 expression.

\section{Transfection of siFoxp3-I BI6FIO cell line (BI6FI0.I)}

The B16F10 cell line containing the silenced Foxp3 was named B16F10.1 and was maintained with G418 antibiotic selection during the study. The levels of Foxp3 mRNA and protein expression were evaluated by qRT-PCR ( 0.235 -fold) and flow cytometry $(0.02 \%)$. The results were significantly lower $(P<0.05)$ than B16F10 WT cells (onefold and 1.4\%, respectively; Figure $4 \mathrm{~A}$ and $\mathrm{B}$ ).

\section{Effects of silencing Foxp3 on cell growth, CD25+ expression, and cytokine production}

Silencing Foxp3 significantly decreased cell proliferation as evaluated by trypan blue staining in the B16F10.1 cell line at 0 hour $\left(2.5 \times 10^{5}\right.$ cells $), 24$ hours $\left(2.7 \times 10^{5}\right.$ cells $), 48$ hours $\left(3.4 \times 10^{5}\right.$ cells $)$, and 72 hours $\left(6.38 \times 10^{5}\right.$ cells $)$. This decrease was lower than that in B16F10 WT cells, as follows: 0 hours $\left(2.5 \times 10^{5}\right.$ cells $), 24$ hours $\left(5.9 \times 10^{5}\right.$ cells $), 48$ hours $\left(9.2 \times 10^{5}\right.$ cells $)$, and 72 hours $\left(15 \times 10^{5}\right.$ cells; Figure 5$)$. 


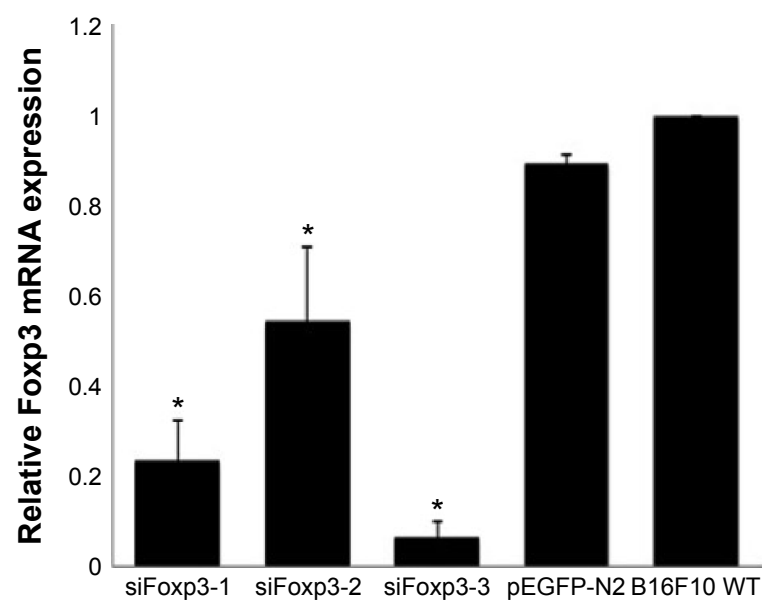

Figure 3 Effect of silencing Foxp3 mRNA expression in BI6FI0 murine melanoma cells.

Notes: The BI6FI0 WT melanoma cells were transfected with recombinant plasmids (siFoxp3-1, siFoxp3-2, and siFoxp3-3). Thereafter, the melanoma cells were analyzed for Foxp3 mRNA expression by qRT-PCR and normalized to $\beta$-actin as an endogenous control; the plasmid pEGFP-N2 and BI6FI0 WT cells were used as control. The data represent the mean number from three repeat samples $(* P<0.005)$.

Abbreviations: qRT-PCR, quantitative real-time reverse transcription-polymerase chain reaction; WT, wild type; siFoxp3, small interference Foxp3 I-3; pEGFP-N2, plasmid of expression green fluorescence protein-N2.

$\mathrm{CD} 25^{+}$expression significantly decreased in B16F10.1 cells $(0.06 \%)$ compared with B16F10 WT cells $(0.69 \%$; Figure 6). IL-2 production was only affected $(P<0.05)$ in the B16F10.1 cell line $(72.35 \mathrm{pg} / \mathrm{mL})$ compared with B16F10 WT cells ( $86.41 \mathrm{pg} / \mathrm{mL})$, and there was no difference $(P<0.05)$ in the other evaluated cytokines: B16F10 WT cells (TGF- $\beta$ [2.85 pg/mL], IL-10 [1.75 pg/mL], and INF- $\gamma$ $[2.45 \mathrm{pg} / \mathrm{mL}]$ ) and B16F10.1 cells (TGF- $\beta$ [2.73 pg/mL], IL-10 [1.72 pg/mL], and INF- $\gamma[2.55 \mathrm{pg} / \mathrm{mL}]$; Figure 7).

\section{Inoculation with BI6FI0.I cell line}

Subcutaneous inoculation of B16F10.1 cell line into C57BL/6 mice delayed the time of visible tumor appearance (day 19 post inoculation; Figure $8 \mathrm{~A}$ and $\mathrm{B}$ ), increased the time of survival (day 51 post inoculation; Figure 9C), and affected the weight of tumors (at days 7 [0.45 g], 14 [2.14 g], 21 [3.13 g], and 28 [4.13 g]; Figure 9A and B) compared with mice inoculated with the B16F10 WT cell line. In the B16F10 WT cell line, visible tumor appearance increased at day 11 post inoculation (Figure $8 \mathrm{~A}$ and $\mathrm{B}$ ), the time of survival was day 39 post inoculation (Figure 9C), and the weights of the tumors were $0.85 \mathrm{~g}$ (day 7), $2.39 \mathrm{~g}$ (day 14), and $7.31 \mathrm{~g}$ (day 21; Figure 9A and B).

\section{Foxp3 expression in tumors}

After inducing tumors in mice by the inoculation of B16F10 WT or B16F10.1 cell lines, the mice were euthanized at different times to evaluate Foxp3 expression in the tumors using qRT-PCR. The relative Foxp3 expression level increased in B16F10 WT cell line in a time-dependent manner $(P<0.05)$ during tumor growth, as follows: 7 days (onefold), 14 days (21.9-fold), and 21 days (196.7-fold) post tumor appearance. The B16F10.1 cell line had a decrease in the relative Foxp3
A

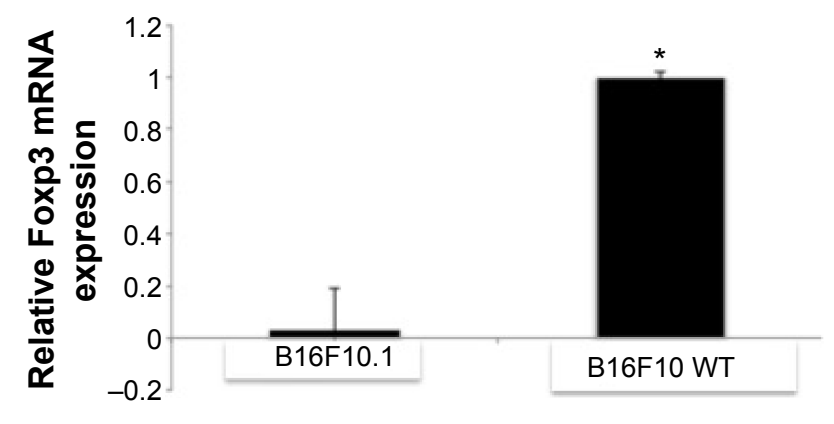

B
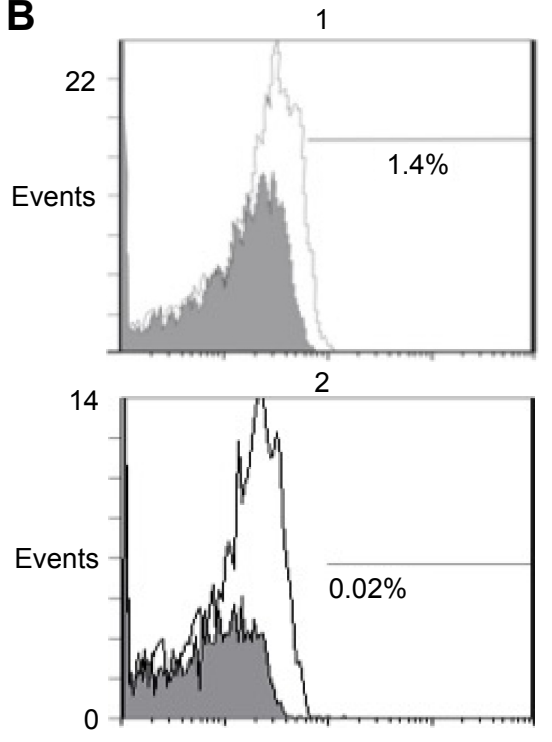

Figure 4 Foxp3 mRNA and protein expression in BI6FI0.I cells.

Notes: (A) The BI6FI0.I cell line was analyzed for mRNA Foxp3 expression by qRT-PCR and normalized to $\beta$-actin as an endogenous control, and BI6FI0 WT cells were used as a positive control. The data represent the mean number from three repeat samples $(* P<0.05)$. (B-I) BI6FI0 WT and (B-2) BI6FI0.I cells were permeabilized and stained for Foxp3 (Foxp3 PECy5; eBioscience). Thereafter, they were analyzed by flow cytometry. The white curve represents specific staining for Foxp3, and the gray curve represents the isotype control.

Abbreviations: qRT-PCR, quantitative real-time reverse transcription-polymerase chain reaction; WT, wild type; PECy5, phycoerythrin cyanine 5. 


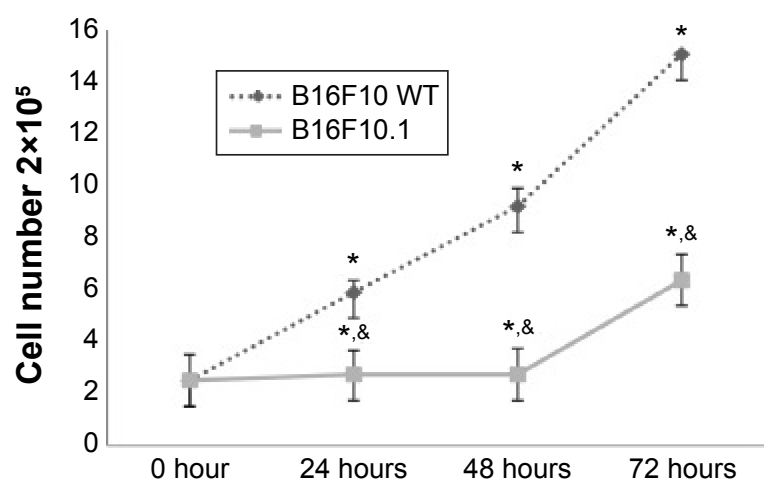

Figure 5 Analysis of proliferation of BI6FIO WT and BI6FI0.I cells.

Notes: BI6FIO WT and BI6FI0.I cells $\left(2 \times 10^{5}\right.$ cells/well) were seeded in six-well plates and incubated at $37^{\circ} \mathrm{C}$ in a $5 \% \mathrm{CO}_{2}$ atmosphere. Thereafter, the cells were counted by trypan blue exclusion staining at 24 hours, 48 hours, and 72 hours of incubation. ( $* P<0.05$ between each cell line) ( ${ }^{\&} P<0.05$ between cell lines).

Abbreviations: WT, wild type; $\mathrm{CO}_{2}$, carbon dioxide.

expression level during the 7 days (onefold), 14 days (1.03-fold), and 21 days ( 0.26 -fold) of tumor growth compared with the B16F10 WT cell line, but the relative Foxp3 expression level increased at day 28 (12.9-fold; Table 1). To remove the influence of TILs on the Foxp3 expression level, we positively selected lymphocytes using Dynabeads and evaluated the Foxp3 expression by flow cytometry. The results of this analysis showed the same pattern of Foxp3 expression: increased expression during melanoma growth at 7 days (1.47\%), 14 days (21.57\%), and 21 days (89.25\%) in intratumoral B16F10 WT cells, while intratumoral B16F10.1 cells had a decrease in Foxp3 expression during the 7 days $(0.02 \%), 14$ days $(0.04 \%)$, and 21 days $(0.40 \%)$ of tumor

A B16F10 WT

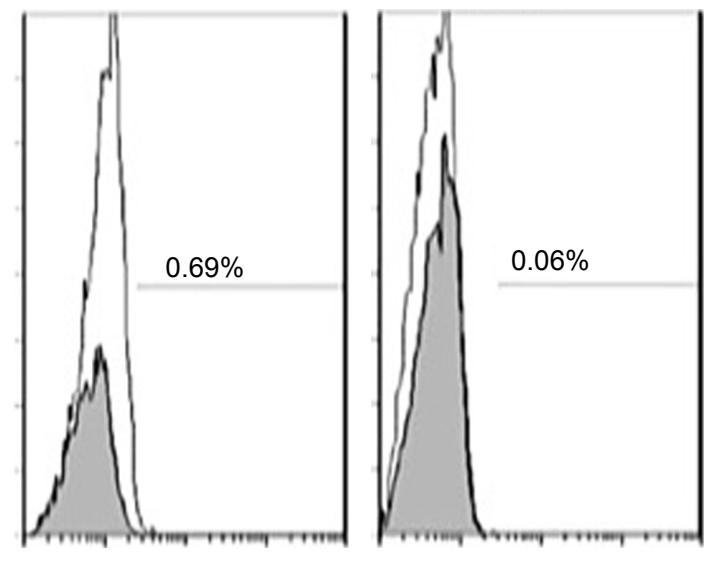

\section{CD25}

Figure $6 \mathrm{CD} 25$ analysis.

Notes: CD25 expression was evaluated in (A) BI6FI0 WT and (B) BI6FI0.I cells by flow cytometry. The percentage of $C D 25^{+}$cells is shown. The white curve represents specific staining for $\mathrm{CD}_{2} 5^{+}$cells, and the gray curve represents the isotype control.

Abbreviations: WT, wild type; CD25, cluster of differentiation-25.

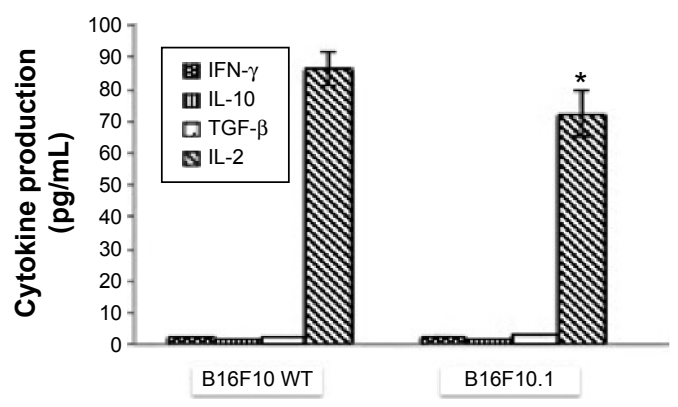

Figure 7 Cytokine production in $\mathrm{BI} 6 \mathrm{FIO} \mathrm{WT}$ and $\mathrm{BI} 6 \mathrm{FIO}$.I cell lines. Notes: BI6FIO WT and BI6FI0.I cells $\left(2.5 \times 10^{5}\right.$ cells/well) were seeded in six-well plates and incubated at $37^{\circ} \mathrm{C}$ in a $5 \% \mathrm{CO}_{2}$ atmosphere for 48 hours. Thereafter, the cell supernatants were collected and used for analysis of cytokines (IL-2, INF- $\gamma$, TGF- $\beta$, and IL-I0) by ELISA $(* P<0.05)$.

Abbreviations: WT, wild type; $\mathrm{CO}_{2}$, carbon dioxide; ELISA, enzyme-linked immunosorbent assay; IL-2, interleukin-2; INF- $\gamma$, interferon gamma; TGF- $\beta$, transforming growth factor beta.

growth. However, Foxp3 expression increased at day 28 (12.82\%; Table 1).

\section{CD25+ expression in tumors}

The expression of $\mathrm{CD} 25^{+}$was evaluated in intratumoral B16F10 cell lines after the positive selection of lymphocytes by Dynabeads. The expression was higher during melanoma growth at 7 days $(1.47 \%), 14$ days $(21.57 \%)$, and 21 days (89.25\%; Table 1) in intratumoral B16F10 WT cells $(P<0.05)$. The intratumoral B16F10.1 cells revealed a decreased $\mathrm{CD}_{2} 5^{+}$expression at 7 days $(0.0 \%), 14$ days (0.04\%), 21 days $(0.04 \%)$, and 28 days $(0.40 \%)$ of tumor growth compared with intratumoral B16F10 WT cells $(P<0.05$; Table 1$)$.

\section{Cytokine production}

The cytokine production in tumors induced by B16F10 WT or B16F10.1 cells was determined. Increased amounts of IL-10 and IL-2 in a time-dependent manner $(P<0.05)$ were observed, whereas IFN- $\gamma$ production was decreased and the production of TGF- $\beta$ was not affected $(P<0.05$; Table 2$)$. However, the production of IL-10, IL-2, and TGF- $\beta$ from tumors induced by B16F10.1 cells was lower than that in tumors induced by B16F10 WT cells, whereas INF- $\gamma$ production was higher in tumors induced by B16F10.1 cells during melanoma growth than in tumors induced by B16F10 WT cells $(P<0.05$; Table 2$)$.

\section{Evaluation of $\mathrm{CD}^{+} \mathrm{TIL}$ populations}

The levels of Foxp3 expression in tumors induced by $\mathrm{B} 16 \mathrm{~F} 10 \mathrm{WT}$ or $\mathrm{B} 16 \mathrm{~F} 10.1$ cells affected the $\mathrm{CD} 4^{+}$ TIL population numbers. There was an increase in the population of lymphocytes $\left(\mathrm{CD} 4^{+}, \mathrm{CD} 4^{+} \mathrm{CD} 25^{+}\right.$, and 


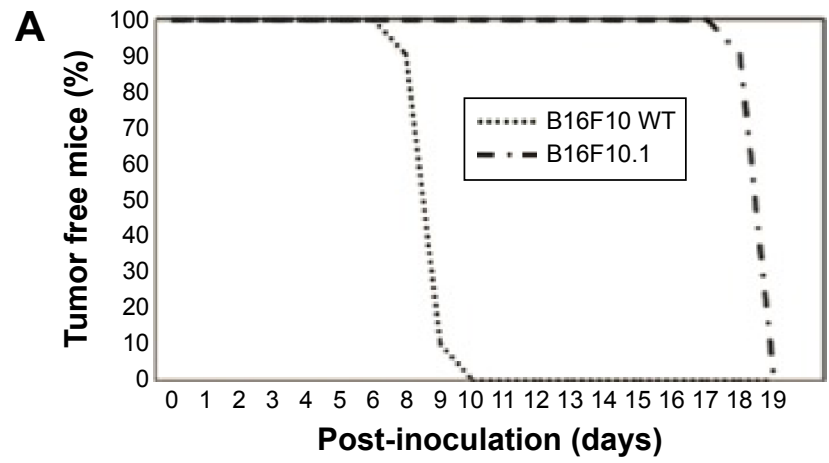

B Implantation melanoma cells $\left(5 \times 10^{5}\right.$ cells $)$
$\begin{array}{ll}\text { B16F10 WT } n=21 & \text { Tumor appearance } \\ \text { B16F10.1 } n=21 & \text { implantation with B16F10. }\end{array}$

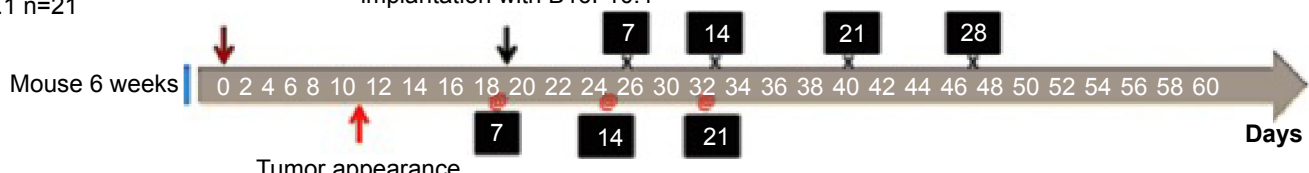

Tumor appearance

implantation with B16F10 WT

Sacrificed mice at $7,14,21$, and 28 days post tumor appearance implanted with B16F10.1 cells
Sacrificed mice at 7,14 , and 21 , days post tumor appearance implanted with B16F10 WT cells

Figure 8 Visible tumor appearance.

Notes: (A) Two groups of mice (ten mice per group) were subcutaneously inoculated in the right flank with BI6FI0 WT or BI6FI0.I cells $\left(5 \times 10^{5}\right.$ cells $\left./ 200 \mu \mathrm{L}\right)$, respectively, and the percentage of tumor-free mice post cell inoculations was determined. The time of tumor appearance was calculated. (B) The time line shows the days of cell inoculations, time of tumor appearance, the days of euthanasia, and collection of spleens and tumors in both murine models.

Abbreviation: WT, wild type.

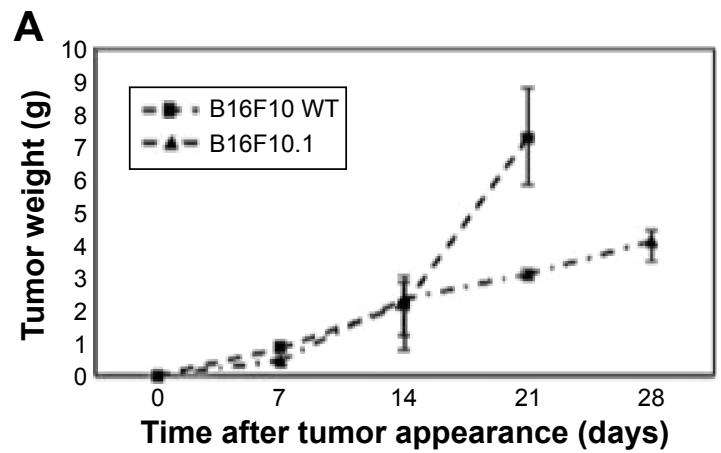

B Tumors (days)

B16F10 WT

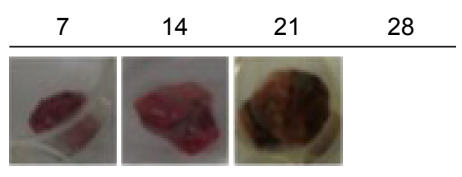

B16F10.1
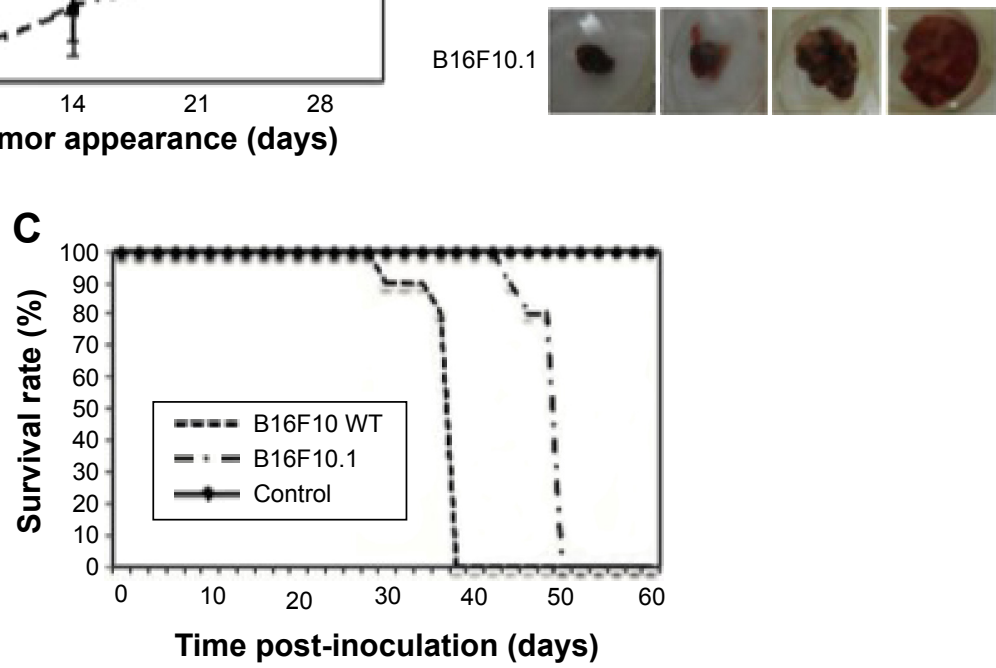

Figure 9 Effect of BI6FIO WT and BI6FI0.I cell inoculations in C57BL/6 mice.

Notes: (A) Two groups of mice (ten in each group) were inoculated with BI6FIO WT or BI6FI0.I melanoma cells ( $5 \times 10^{5}$ cells). Thereafter, the tumors were surgically removed during melanoma growth (7 days, 14 days, and 21 days in mice injected with BI6FIO WT cells and 7 days, 14 days, 21 days, and 28 days in mice injected with BI6FI0.I cells) in both groups and the time of tumor appearance was calculated. (B) Visual observation of tumors collected during melanoma growth from each group. (C) The survival rate of C57BL/6 mice bearing melanoma tumors. The mice ( $\mathrm{n}=10 /$ group) were injected with BI6FI0 WT or BI6FI0.I melanoma cells ( $5 \times 10^{5}$ cells), and the survival rate was determined in each group. In the control group, the mice were not inoculated.

Abbreviation: WT, wild type. 
Table I Foxp3 expression analysis during melanoma growth

\begin{tabular}{|c|c|c|c|c|c|c|}
\hline $\begin{array}{l}\text { Tumor } \\
\text { collected } \\
\text { (days) }\end{array}$ & $\begin{array}{l}\text { B I6FI0 WT, } \\
\text { relative Foxp3 } \\
\text { expression } \\
\text { level (\%) }\end{array}$ & $\begin{array}{l}\text { B I6FI0.I WT, } \\
\text { relative Foxp3 } \\
\text { expression } \\
\text { level (\%) }\end{array}$ & $\begin{array}{l}\text { B I6FI0 WT } \\
\text { without T-cells, } \\
\text { Foxp3 expression } \\
\text { level (\%) }\end{array}$ & $\begin{array}{l}\text { B I6FI0.I WT } \\
\text { without T-cells, } \\
\text { Foxp3 expression } \\
\text { level (\%) }\end{array}$ & $\begin{array}{l}\text { B I6FI0 WT } \\
\text { without T-cells, } \\
\text { CD25+ expression } \\
\text { level (\%) }\end{array}$ & $\begin{array}{l}\text { BI6FI0.I WT } \\
\text { without T-cells, } \\
\text { CD25+ expression } \\
\text { level (\%) }\end{array}$ \\
\hline 7 & I $( \pm 0.03)$ & $I( \pm I . I 2)$ & 1.478 & 0.02 & 1.47 & 0 \\
\hline 14 & $21.9( \pm 0.5)^{*}$ & $1.03( \pm 1.57)$ & $21.57 *$ & 0.04 & $21.57^{*}$ & 0.04 \\
\hline 21 & $196.7( \pm 0.01)^{*}$ & $0.26( \pm 0.4)^{*}$ & $89.25^{*}$ & $0.4^{*}$ & $89.25^{*}$ & 0.04 \\
\hline 28 & & $12.9( \pm 0.3)^{*}$ & & $12.82 *$ & & $0.40 *$ \\
\hline
\end{tabular}

Notes: Tumors induced by BI6FIO WT and BI6FI0.I cells were collected at different times post tumor appearance, and the T-cells were purified by Dynabeads. Thereafter, the relative Foxp3 mRNA expression level was determined by qRT-PCR and analyzed by flow cytometry. Values were normalized. $* P<0.05$.

Abbreviations: WT, wild type; qRT-PCR, quantitative real-time reverse transcription-polymerase chain reaction.

$\left.\mathrm{CD} 4^{+} \mathrm{CD} 25^{+} \mathrm{FOXP}^{+}\right)$in a time-dependent manner $(P<0.05)$ in the tumors induced by B16F10 WT cells (Table 3). In tumors induced by B16F10.1 cells, the cell numbers did not change significantly $(P<0.05)$ in $\mathrm{CD} 4^{+}, \mathrm{CD} 4^{+} \mathrm{CD} 25^{+}$, and $\mathrm{CD} 4{ }^{+} \mathrm{CD} 25^{+} \mathrm{FOXP} 3^{+}$populations $(P<0.05$; Table 3$)$. The percentages of $\mathrm{T} \mathrm{CD}^{+}$lymphocyte populations were lower in tumors from mice inoculated with B16F10.1 cells than those in mice inoculated with B16F10 WT cells during melanoma growth (Table 3).

\section{Evaluation of $\mathrm{T} \mathrm{CD}^{+}$positive cells in spleen}

The population levels of $\mathrm{T} \mathrm{CD}^{+}$positive cells were evaluated in spleens from mice inoculated with B16F10 WT or B16F10.1 cells. There was a decrease in the $\mathrm{CD}^{+}$population at 14 days and an increase at 21 days compared to that at 7 days in mice inoculated with B16F10 WT cells. The populations of $\mathrm{CD} 4{ }^{+} \mathrm{CD} 25^{+}$and $\mathrm{CD} 4{ }^{+} \mathrm{CD} 25^{+} \mathrm{FOXP} 3^{+}$were not significantly different $(P>0.05)$ during melanoma growth in spleens of mice inoculated with B16F10 WT cells (Table 3). The population of $\mathrm{T} \mathrm{CD} 4^{+}$cells increased in a time-dependent manner and did not show significant changes in $\mathrm{CD} 4^{+} \mathrm{CD} 25^{+}$ and $\mathrm{CD} 4{ }^{+} \mathrm{CD} 25^{+} \mathrm{FOXP} 3{ }^{+}$populations until 28 days, when there was an increase in $\mathrm{CD} 4^{+} \mathrm{CD} 25^{+} \mathrm{FOXP} 3^{+}$populations in mice inoculated with B16F10.1 cells (Table 3). The $\mathrm{T} \mathrm{CD}^{+}$cell populations at 7 days and 21 days were higher in spleen cells of mice inoculated with B16F10 WT cells compared to those in mice inoculated with B16F10.1 cells. At 14 days, the population was lower in mice inoculated with B16F10 WT compared with mice inoculated with B16F10.1 cells and did not show significant changes between $\mathrm{CD} 4{ }^{+} \mathrm{CD} 25^{+}$and $\mathrm{CD} 4^{+} \mathrm{CD} 25^{+} \mathrm{FOXP} 3^{+}$ populations from mice inoculated with B16F10 WT cells and mice inoculated with B16F10.1 cells (Table 3).

\section{Discussion and conclusion}

In this study, a cellular clone of B16F10.1 cells was obtained by transfection with siFoxp3-1 plasmid for silencing Foxp3, with the purpose of determining the role of Foxp3 expression in tumor cells. This is a controversial topic, with in vitro studies pointing to an oncosuppressive action, whereas studies conducted on human samples associate Foxp3 expression by tumor cells with metastatic spread. ${ }^{9}$

The plasmid siFoxp3-3 decreased the relative cell viability of B16F10 cells (94.99\%) and was not optimal for the establishment of a cellular clone. These findings are controversial because an increase ${ }^{10}$ or decrease ${ }^{11}$ of Foxp3 expression

Table 2 Production of cytokines in tumors induced by BI6FIO WT and BI6FI0.I cells during melanoma growth

Tumors induced by B I6FIO WT cells

\section{Days post tumor appearance}

Cytokines (pg/mL)

IL- 10

IL-2

TGF- $\beta$

INF- $\gamma$

$20.38 \pm 1.20$

Notes: The tumors induced by BI6FI0 WT cells were collected at 7 days, I4 days, and 21 days, and the tumors induced by BI6FI0.I cells were collected at 7 days, 14 days, 21 days, and 28 days post tumor appearance. Thereafter, the production of cytokines (IL-10, IL-2, TGF- $\beta$, and INF- $\gamma$ ) was measured by ELISA experiments (according to the manufacturer's instructions) in the supernatants of tumors. The data are expressed as the mean of three independent experiments in the supernatants of murine melanoma tumors collected during melanoma growth in vivo. $* P<0.05$ indicates a significant difference between the days of melanoma growth.

Abbreviations: WT, wild type; ELISA, enzyme-linked immunosorbent assay; IL-10, interleukin I0; IL-2, interleukin 2; TGF- $\beta$, transforming growth factor beta; INF- $\gamma$, interferon gamma. 
Table 3 Evaluation of $\mathrm{CD}^{+}$cell population from positive tumor-infiltrating lymphocytes and spleen of C57BL/6 mice inoculated with BI6FIO WT and BI6FI0.I cells during tumor growth

\begin{tabular}{|c|c|c|c|c|c|c|}
\hline $\begin{array}{l}\text { Tumor } \\
\text { collected (days) }\end{array}$ & $\begin{array}{l}\text { TIL CD4 }^{+} \\
\text {frequency }(\%)\end{array}$ & $\begin{array}{l}\text { TIL CD4 }{ }^{+} \text {CD25 } \\
\text { frequency }(\%)\end{array}$ & $\begin{array}{l}\text { TIL CD4 }{ }^{+} \text {CD25 } 5^{+} \text {Foxp }^{+} \\
\text {frequency }(\%)\end{array}$ & $\begin{array}{l}\text { Spleen CD4 } \\
\text { frequency (\%) }\end{array}$ & $\begin{array}{l}\text { Spleen CD4 }{ }^{+} \text {CD25+ } \\
\text { frequency }(\%)\end{array}$ & $\begin{array}{l}\text { Spleen CD4 }{ }^{+} \text {CD } 25^{+} \text {Foxp3 } \\
\text { frequency }(\%)\end{array}$ \\
\hline \multicolumn{7}{|c|}{ BI6FI0 WT melanoma } \\
\hline 7 & $0.12 \pm 0.02$ & $1.02 \pm 0.03$ & $0.49 \pm 0.01$ & $|4.35 \pm 0.2|$ & $1.98 \pm 0.01$ & $0.32 \pm 0.04$ \\
\hline 14 & $0.19 \pm 0.01$ & $4.12 \pm 0.1 I^{*}$ & $1.57 \pm 0.0 \mathrm{I}^{*}$ & $9.53 \pm 0.10^{*}$ & $2.26 \pm 0.23$ & $0.15 \pm 0.01 *$ \\
\hline 21 & $3.90 \pm 0.15^{*}$ & $9.21 \pm 0.14^{*}$ & $1.74 \pm 0.06 *$ & $|8.5| \pm 0.40^{*}$ & $2.52 \pm 0.10$ & $0.53+0.01 *$ \\
\hline \multicolumn{7}{|c|}{ BI6FI0.I melanoma } \\
\hline 7 & $0.14 \pm 0.06$ & $0.09 \pm 0.01 *$ & $0 \pm 0.01 *$ & $9.29 \pm 0.01$ & $2.04 \pm 0.08$ & $0.15 \pm 0.08$ \\
\hline 14 & $0.20 \pm 0.03$ & $0.29 \pm 0.01 *$ & $0.02 \pm 0.01 *$ & $|3.35 \pm 0.2|^{*}$ & $2.2 \pm 0.14$ & $0.57 \pm 0.08 *$ \\
\hline 21 & $0.13 \pm 0.04$ & $0.18 \pm 0.02$ & $0.14 \pm 0.03 *$ & $14.16 \pm 0.16 *$ & $2.54 \pm 0.06$ & $0.8 \pm 0.07 *$ \\
\hline 28 & $0.14 \pm 0.06$ & $0.19 \pm 0.01$ & $0.17 \pm 0.03$ & $15.35 \pm\left. 0.2\right|^{*}$ & $2.7 \pm 0.14$ & $1.08 \pm 0.08^{*}$ \\
\hline
\end{tabular}

Notes: Tumors and spleen were collected at 7, I4, and 2I days from BI6FIO WT and BI6FI0.I melanoma. TIL's from each tumor were obtained using magnetic separation, and then the total spleen cells were analyzed. Thereafter, cellular populations were analyzed by flow cytometry using the Mouse Regulatory T-cell staining (PE-Cy5 Foxp3, FITC CD4 $\left.{ }^{+}, \mathrm{PE} C D 25\right)$ kit(eBioscience). $* P<0.05$. Data presented as mean \pm standard deviation.

Abbreviations: WT, wild type; TIL's, tumor-infiltrating lymphocytes; PE-Cy5, phycoerythin-cyanine 5; Foxp3, Forkhead box p3; FITC CD4+, fluorescein isothiocyanate cluster differentiation 4; PE, phycoerythrin.

has been associated with cellular death, suggesting that the action is dependent on the primer design. The silencing of Foxp3 reduced Foxp3 expression and cellular proliferation and decreased the expression of $\mathrm{CD} 25^{+}$and IL-2 production compared with B16F10 WT cells. These results were in agreement with those reported previously by Miranda-Hernandez et al, 2013, where Foxp3 and CD25+ expression and IL-2 production correlated with tumor growth. ${ }^{12}$ In lymphocytes, Foxp3 interacts with the nuclear factor of activated T-cells (NFAT) to induce suppressive molecules such as IL-10, TGF- $\beta$, cytotoxic T-lymphocyte antigen 4 (CTLA-4), and $\mathrm{CD} 25^{+}$, maintaining the anergic features and suppressive functions of Tregs. ${ }^{13}$ In melanoma cells, apoptosis is triggered by CsA or NFATc2 silencing, suggesting that NFAT could be a therapeutic target in melanoma. ${ }^{9}$ However, there was no difference $(P<0.05)$ in the production of cytokines such as TGF- $\beta$, IL-10, and INF- $\gamma$ in B16F10 WT and B16F10.1 cells, suggesting that IL-2 and its receptor $\mathrm{CD} 25^{+}$play a role in melanoma proliferation in a Foxp3 expression-dependent manner. The effect of silencing of Foxp3 on tumor proliferation was corroborated in vivo, when the B16F10.1 cells were subcutaneously inoculated into mice. This treatment significantly delayed $(P<0.05)$ the time of visible tumor appearance, increased the time of survival, and decreased the tumor weight compared with B16F10 WT cells. These results are different compared to other studies that reported that Foxp3 inhibits breast tumor growth by directly repressing the transcription activity of two oncogenes, HER 2 and $S K P 2$, while inducing the transcription activity of the tumor suppressor gene $\mathrm{p} 21 .{ }^{14}$ Foxp3 has been identified as an $\mathrm{X}$-linked tumor suppressor gene for both breast cancer and prostate cancer and has been proposed as a strategy to address the reactivation of Foxp3 for cancer therapy. ${ }^{15}$

Foxp3 expression was lower in B16F10.1 cells derived from tumors than in B16F10 WT cells. These results confirm those reported by our team, ${ }^{12}$ suggesting that Foxp3 could play a role in melanoma growth. On the other hand, the expression of the cytokines IL-10, IL-2, and TGF- $\beta$ and CD25+ were lower in melanomas derived from B16F10.1 cell clones than in melanomas derived from $\mathrm{B} 16 \mathrm{~F} 10 \mathrm{WT}$ cells during tumor growth, although INF- $\gamma$ production was higher. In lymphocytes, but not melanomas, previous reports indicated that Foxp3 forms complexes with the Rel family transcription factors NFAT and nuclear factor-kappa B and blocks their ability to activate IL-2 and INF- $\gamma$ transcription. ${ }^{16}$ In contrast to this, our results suggest that Foxp3 plays a more complex role in melanoma cells than in lymphocytes and partly modulates the interaction with other transcription factors related to cytokine production and expression of $\mathrm{CD} 25^{+}$. The populations of $\mathrm{CD} 4^{+}$TILs $\left(\mathrm{CD} 4^{+}, \mathrm{CD} 4^{+} \mathrm{CD} 25^{+}\right.$, and $\left.\mathrm{CD} 4^{+} \mathrm{CD} 25^{+} \mathrm{Foxp}^{+}\right)$ were lower in melanomas derived from B16F10.1 cells than in melanomas derived from B16F10 WT cells, which is related to the type and amount of cytokines secreted by the tumor cells. Similar results were observed in spleens until 28 days, when the $\mathrm{CD} 4^{+} \mathrm{CD} 25^{+} \mathrm{Foxp} 3^{+}$cells increased in mice inoculated with B16F10.1 cells. Other studies have shown that coculture of Foxp3-expressing melanoma cells with naive $\mathrm{CD}^{+}{ }^{+} \mathrm{CD} 25^{+} \mathrm{T}$-cells resulted in a strong Foxp3-dependent inhibition of T-cell proliferation, ${ }^{17}$ when the cells were either in contact or separated using Transwells.

In this study, Foxp3 induced tumor growth in melanoma cells by modifying the immune system at the local and 
peripheral level, shifting the environment toward an immunosuppressive profile. Therapies based on this transcription factor could be strategies for melanoma treatment, although similar studies in human melanoma cell lines should be undertaken to corroborate these findings.

\section{Acknowledgments}

This work was supported by the Immunology and Virology Department, Biological Sciences Faculty, University Autonomous of Nuevo León in collaboration with "Red Temática de Inmunología en Cáncer y Enfermedades Infecciosas" with registry number 253053, CONACYT.

\section{Author contributions}

All authors contributed toward data analysis, drafting and critically revising the paper and agree to be accountable for all aspects of the work.

\section{Disclosure}

The authors report no conflicts of interest in this work.

\section{References}

1. Karanikas V, Speletas M, Zamanakou M, et al. Foxp3 expression in human cancer cells. J Transl Med. 2008;6:19.

2. Zhang B, Dou Y, Xu X, et al. Endogenous FOXP3 inhibits cell proliferation, migration and invasion in glioma cells. Int J Clin Exp Med. 2015;15:1792-1802.

3. Hinz S, Pagerols-Raluy L, Oberg HH, et al. Foxp3 expression in pancreatic carcinoma cells as a novel mechanism of immune evasion in cancer. Cancer Res. 2007;67:8344-8350.

4. Ebert LM, Tan BS, Browning J, et al. The regulatory T cell-associated transcription factor FoxP3 is expressed by tumor cells. Cancer Res. 2008; 68:3001-3009.
5. Gavin MA, Torgerson TR, Houston E, et al. Single-cell analysis of normal and FOXP3-mutant human T cells: FOXP3 expression without regulatory T cell development. Proc Natl Acad Sci U S A. 2006;103:6659-6664.

6. Ahmadzadeh M, Antony PA, Rosenberg SA. IL-2 and IL-15 each mediate de novo induction of FOXP3 expression in human tumor antigen-specific CD8 T cells. J Immunother. 2007;30:294-302.

7. Ahmadzadeh M, Felipe-Silva A, Heemskerk B, et al. FOXP3 expression accurately defines the population of intratumoral regulatory $\mathrm{T}$ cells that selectively accumulate in metastatic melanoma lesions. Blood. 2008; 112:4953-4960

8. Coombes JL, Siddiqui KR, Arancibia-Carcamo CV, et al. A functionally specialized population of mucosal CD103+ DCs induces Foxp3+ regulatory $\mathrm{T}$ cells via a TGF-beta and retinoic acid-dependent mechanism. J Exp Med. 2007;204:1757-1764.

9. Triulzi T, Tagliabue E, Balsari A, Casalini P. FOXP3 expression in tumor cells and implications for cancer progression. J Cell Physiol. 2013;228(1):30-35.

10. Ma GF, Miao Q, Liu YM, et al. High FoxP3 expression in tumour cells predicts better survival in gastric cancer and its role in tumour microenvironment. Br J Cancer. 2014;110:1552-1560.

11. Douglass S, Meeson AP, Overbeck-Zubrzycka D, et al. Breast cancer metastasis: demonstration that FOXP3 regulates CXCR4 expression and the response to CXCL12. J Pathol. 2014;234:74-85.

12. Miranda-Hernández DF, Franco-Molina MA, Mendoza-Gamboa E, et al. Expression of Foxp3, CD25 and IL-2 in the B16F10 cancer cell line and melanoma is correlated with tumor growth in mice. Oncol Lett. 2013;6(5):1195-1200.

13. Lee SM, Gao B, Fang D. FoxP3 maintains Treg unresponsiveness by selectively inhibiting the promoter DNA-binding activity of AP-1. Blood. 2008;111(7):3599-3606.

14. Liu R, Wang L, Chen G, et al. FOXP3 up-regulates p21 expression by site-specific inhibition of histone deacetylase 2/histone deacetylase 4 association to the locus. Cancer Res. 2009;69:2252-2259.

15. Wang L, Liu R, Ribick M, Zheng P, Liu Y. FOXP3 as an X-linked tumor suppressor. Discov Med. 2010;10(53):322-328.

16. Soligo M, Camperio C, Caristi S, et al. CD28 costimulation regulates FOXP3 in a RelA/NF-kappaB-dependent mechanism. Eur J Immunol. 2011;41:503-513.

17. Niu J, Jiang C, Li C, et al. Foxp3 expression in melanoma cells as a possible mechanism of resistance to immune destruction. Cancer Immunol Immunother. 2011;60(8):1109-1118.
OncoTargets and Therapy

\section{Publish your work in this journal}

OncoTargets and Therapy is an international, peer-reviewed, open access journal focusing on the pathological basis of all cancers, potential targets for therapy and treatment protocols employed to improve the management of cancer patients. The journal also focuses on the impact of management programs and new therapeutic agents and protocols on

\section{Dovepress}

patient perspectives such as quality of life, adherence and satisfaction. The manuscript management system is completely online and includes a very quick and fair peer-review system, which is all easy to use. Visit http://www.dovepress.com/testimonials.php to read real quotes from published authors. 